\title{
Diversity of Grasses as Producers of Atmospheric Aerosol Pollen Component
}

\author{
${\text { Galina } \text { Zueva }^{1 *} \text { and Vladimir Golovko }}^{2}$ \\ ${ }^{1}$ Central Siberian Botanical Garden, SB RAS, 630090, Novosibirsk, Russia \\ ${ }^{2}$ Voevodsky Institute of Chemical Kinetics and Combustion, SB RAS, 630090, Novosibirsk, Russia
}

\begin{abstract}
The article provides the results of a study dealing with pollen release into the atmosphere by 23 species from 21 genera of the Poaceae Barnh family. The species under investigation are the dominant ones in natural plant communities and are used as components in turf plant ${ }^{\dagger}$ communities and belong to the group of ornamental grasses. Their pollen causes seasonal hay fever (allergic rhinitis), which accounts for the interest in the regularities of its drift. The drift distance is determined by the particles sedimentation velocity and depends on the number of pollen grains they include. The study estimates the cluster composition of pollen particles released into the atmosphere. All species under consideration massively form clusters consisting of two or more grains. Their share was $11,1-50,8 \%$, the share of pollen grains in them was $-21.9-84,0 \%$.
\end{abstract}

\section{Introduction}

Pollen particles are invariably a part of a fraction of primary biogenic aerosol particles, extremely diverse in its composition and origin [1], being the biggest (from 10 to 100 $\mu \mathrm{m}$, in average $-20-40 \mu \mathrm{m}$ ) in size in the group. They play the key role in the process of plant seed reproduction and the exchange of genetic material both within a population and between remote populations. The role of pollen as one of the most widespread and massive fractions of atmospheric aerosol is the transfer of chemical elements within plant communities, their influence on cloud formation and precipitation, and thus on the regional climate in general.

The grass family Poaceae Barnh is one of the largest families of angiosperms plants. It includes about 8000 species and 500 genera distributed among 60-80 tribes and several subfamilies. They are spread all over the world. The grass species under investigation belong to 21 genera of the family and present various climatic zones. The period of pollen release into the atmosphere is determined by flowering dynamics of the plants, and its concentration in the atmosphere correlates with their abundance in vegetation and the amount of pollen they produce. The poaceae that dominate in grassland communities of extra-tropical landmass are characterized by high pollen production - up tо до $300 \mathrm{~kg}$ per hectar [2]. Its peak mass concentrations in Novosibirsk

\footnotetext{
* Corresponding author: zuevagalina70@yandex.ru
} 
region are $10-15 \mu \mathrm{g} / \mathrm{m}^{3}$ (daily average $-3-5 \mu \mathrm{g} / \mathrm{m}^{3}$ ) or $10-15 \%$ (and $3-5 \%$ ) of total mass concentration of atmospheric aerosol [3]. Huge amount of grass pollen released into the atmosphere causes hay fever [4-6]. Continuous growth in the number of hay fever cases stimulates interest in modelling the process of pollen spread in the air [7-8].

Dispersion, transfer and capture of pollen particles by selective surfaces is dependent on their sedimentation rate. A complex shape of pollen grains, which are deformed while drying, makes the theoretical calculation of this parameter extremely complicated. It is especially affected by the formation of clusters of two or more pollen grains. The presence of pollen clusters, dealt with by earlier aeropalynological studies [9], is virtually ignored nowadays while estimating pollen concentration in the atmosphere $[10,11]$ and is not taken into account while developing mathematical models of pollen transfer [7-11]. However, in all experiments involving the dispersion of anemophilous plants' pollen, a considerable number of clusters containing two or more pollen grains has been noted [12]. A considerable amount of pollen clustershave been observed in all samples of the pollen released into the atmosphere [13].

The current study has aimed to: 1) determine the presence of clusters of two or more grains among the pollen particles of grasses released into the atmosphere in natural conditions; 2) evaluate the share of clusters in total amount of pollen particles and 3) the share of pollen grains comprising them in the total amount of collected pollen grainsx, i.e. the cluster composition of grass pollen.

\section{Materials and Methods}

\subsection{Object of study}

While evaluating the cluster composition of pollen aerosol the authors studied the release into the atmosphere of pollen particles from 23 species of poacea (belonging to 21 genera of the family), presented in bioresource scientific "Indoor and Outdoor Collection of Live plants USU 440534 of Central Siberian Botanical Garden, SB RAS. The species under study are the dominant ones in natural plant communities, are used in multi-component turfgrass plant communities or are highly ornamental.

\subsection{Methods of study}

The observations were conducted under environmental conditions. The wind blew the pollen off the grass inflorescences onto substrates covered ith glycerin-gelatin (with addition of a colouring agent kumashi blue) and located $20-25 \mathrm{~cm}$. lower. The speed of the wind gusts at the time of the observation was $0.3-2.0$ meters per second. The substrate was situated in such a way that it could capture the pollen spilled from the inflorescence, the substrate being placed taking into account wind direction. The exposure of the substrates lasted 1-2 seconds. The distance from the inflorescence to the substrate (and the duration of exposure) allows to capture enough particles from the «pollen cloud» blown off the inflorescence (which is as a rule easily noticeable) and to avoid an occasional contact of the substrate with the inflorescence itself. Pollen sampling for each species was repeated five times. The samples were taken from neighboring plants. Time intervals between sampling were about 10-15 minutes. Simultaneously, temperature and relative air humidity were measured with a portable device Center 311 temperature meter. The collected pollen samples were examined with a optical microscope (fig. 1). Pollen particles count was performed on 10 transects with the 20-40-fold increase in the lens. As grass pollen has certain morphological features preventing it from conglutination and cluster formation. The 
authors used F-test to verify the hypothesis about their formation in the process of sedimentation of single grains on the substrate

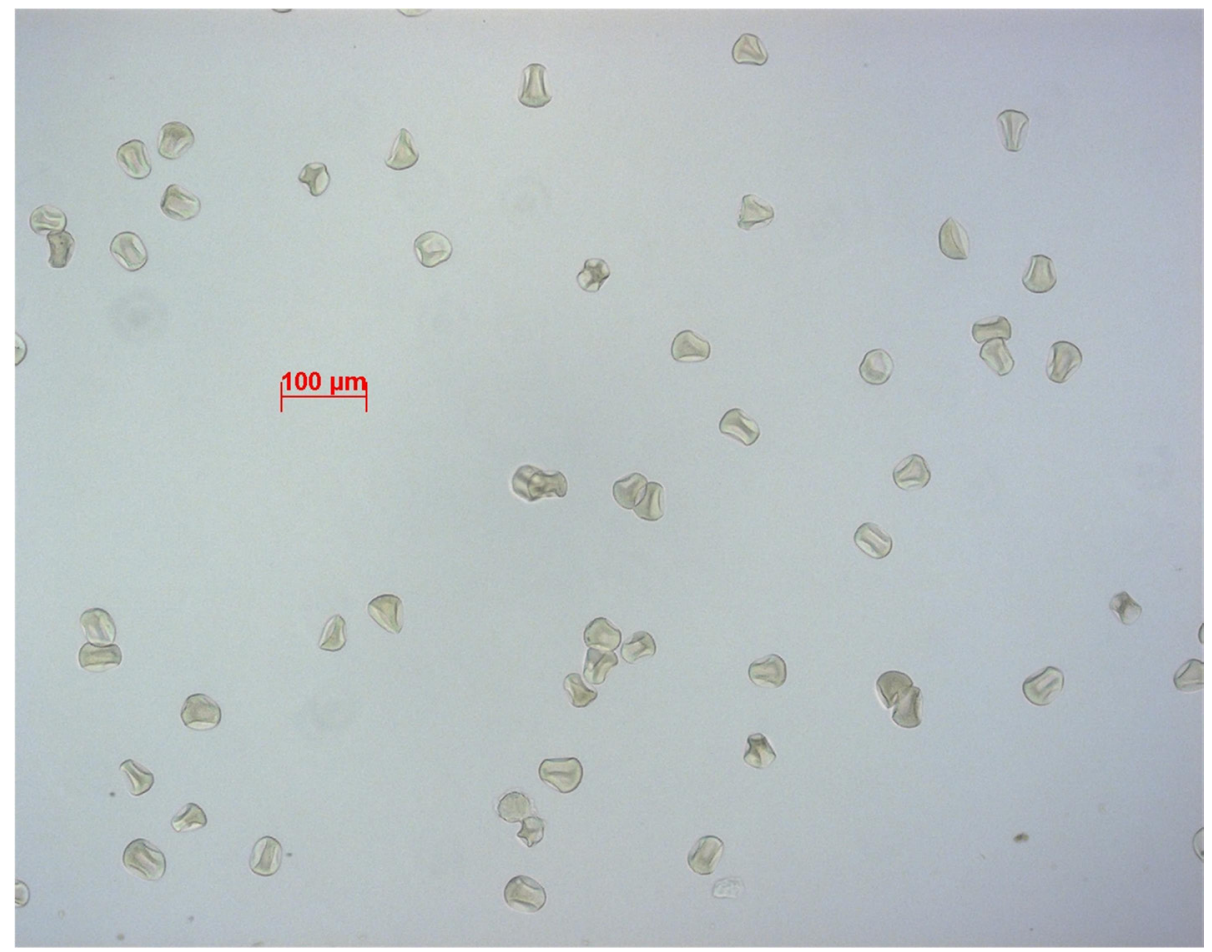

Fig. 1. Dry pollen particles of Elytrigia repens L.

\subsection{Statistical methods}

While estimating the number of clusters from two or more pollen grains, which could have been formed on the substrate during sedimentation, the following assumptions have been made:

1) the sedimentation of a particular pollen grain onto the substrate does not depend on that of other pollen grains;

2) In the cluster being formed, pollen grains are distributed in one layer.

In accordance with these assumptions clusters of $j+1$ pollen grains are formed as a result of the sedimentation on the area, where $\mathrm{j}$ grains had landed previously (where $\mathrm{j}$ is an integer from 0 to $\infty$ ). As a result with the growth in the number of pollen grains in clusters, their quantity on the substrate should decrease. Provided the expectation of the number of clusters formed from the arbitrary pollen grains is less than 1, it means that such (and larger) particles can't be formed on the substrate at the given number of pollen grains per unit area.

A cluster is formed if the distance between the geometrical centers of pollen grains does not exceed two radii. The expectation of the number of clusters formed from two or more grains was estimated on the basis of their number sedimented on the substrate and the share of the total area of their projection to the total area of the substrate. In order to achieve that, the area of individual pollen grains was estimated by photographing $\approx 100-200$ pollen grains of each species under investigation in the Common Use Center for Microscopic Analysis of Biological Objects at Institute of Cytology and Genetics of SB RAS. Their 
projection areas on the photographs were identified by processing the images with MapInfo Professional [16].

For the samples obtained, the F-test values were 3.8 at significance level $\alpha=0.05 ; 6.6$ at significance level $\alpha=0.01$; and 10.8 at significance level $\alpha=0.001$ respectively. If the calculated F-test results exceed the indicated values, zero hypothesis at the given significance level is to be rejected.

\section{Results}

The projection area of sedimented grass pollen grains occupied from hundredths of a percent to $2,2 \%$ of the examined substrate surface. Pollen sediments observed by light microscopy differ drastically in its cluster composition from those which could have been observed/could have appeared had the clusters been formed on the glass slides from single pollen grains sedimented on them. The calculated F-test values for the pollen clusters of the grasses/poaceae under investigation varied from 22.4 to 69.6 and were higher critical values in all series of experiments at the significance level 0.001 .

Basing on the data, the hypothesis about the formation of the pollen clusters directly on the substrate is to be rejected. This implies that the existing morphological adaptations of grasses (dry pollen with thin and smooth exine), aimed at preventing cluster formation in the process of pollination do not actually prevent them from forming, but rather limit the quantity of such particles.

Table 1. F-test Values for the estimation of probability of pollen cluster formation on the substrate.

\begin{tabular}{|l|l|c|c|}
\hline № & \multicolumn{1}{|c|}{ Species name } & $\begin{array}{c}\text { Total number of pollen } \\
\text { grains }\end{array}$ & F-test result, $\mathrm{F}_{\varphi}$ \\
\hline 1 & Agrostis gigantea Roth. & 3971 & 63.1 \\
\hline 2 & Achnatherum splendens Trin. & 711 & 69.6 \\
\hline 3 & Arrhenatherum elatius L. & 1031 & 47.7 \\
\hline 4 & Avena sativa L. & 1321 & 32.0 \\
\hline 5 & Bromopsis inermis Leys. & 931 & 47.1 \\
\hline 6 & Briza maxima L. & 475 & 35.7 \\
\hline 7 & Dactylis glomerata L. & 1957 & 42.4 \\
\hline 8 & Deschampsia caespitosa L. & 565 & 22.4 \\
\hline 9 & Elytrigia repens L. & 4518 & 22.9 \\
\hline 10 & Festuca pratensis Huds. & 1007 & 30.1 \\
\hline 11 & Lolium perenne L. & 798 & 21.5 \\
\hline 12 & Miscanthus sinensis Anderss & 922 & 20.2 \\
\hline 13 & Miscanthus sacchariflorus Benth. & 927 & 24.1 \\
\hline 14 & Panicum virgatum L. & 924 & 21.7 \\
\hline 15 & Phalaris canariensis L. & 2159 & 34.0 \\
\hline 16 & Phalaroides arundinacea L. & 976 & 49.0 \\
\hline 17 & Phleum pratensis L. & 5857 & 53.0 \\
\hline 18 & Poa alpina, L. & 1489 & 40.4 \\
\hline 19 & Poa sylvicola Guss. & 637 & 49.0 \\
\hline 20 & Sesleria coerulea Friv. & 1159 & 51.9 \\
\hline 21 & Setaria italica L. & 872 & 26.3 \\
\hline 22 & Stipa pennata L. & 607 & 32.0 \\
\hline 23 & Zea mays L. & 521 & 33.8 \\
\hline
\end{tabular}

Table 2 provides the results of identification of grass pollen grain cluster composition, which were obtained in while observing the release of their pollen into the atmosphere in natural conditions. All poacea species under investigation always formed some clusters 
from two or more pollen grains. The number of clusters decreased with the increase in the number of particles in the cluster. The minimal number of clusters from two or more pollen grains among grasses was noted with Zea mays L. $-11.1 \%$, and the maximal number of those with Elytrigia repens L. - 56,0\%. The number of pollen grains forming the clusters also varied widely: from $21,9 \%$ with Zea mays, to $85.1 \%$ from the total number of pollen grains sedimented on the substrates with Elytrigia repens.

Table 2. Cluster presence in the emission of grass pollen

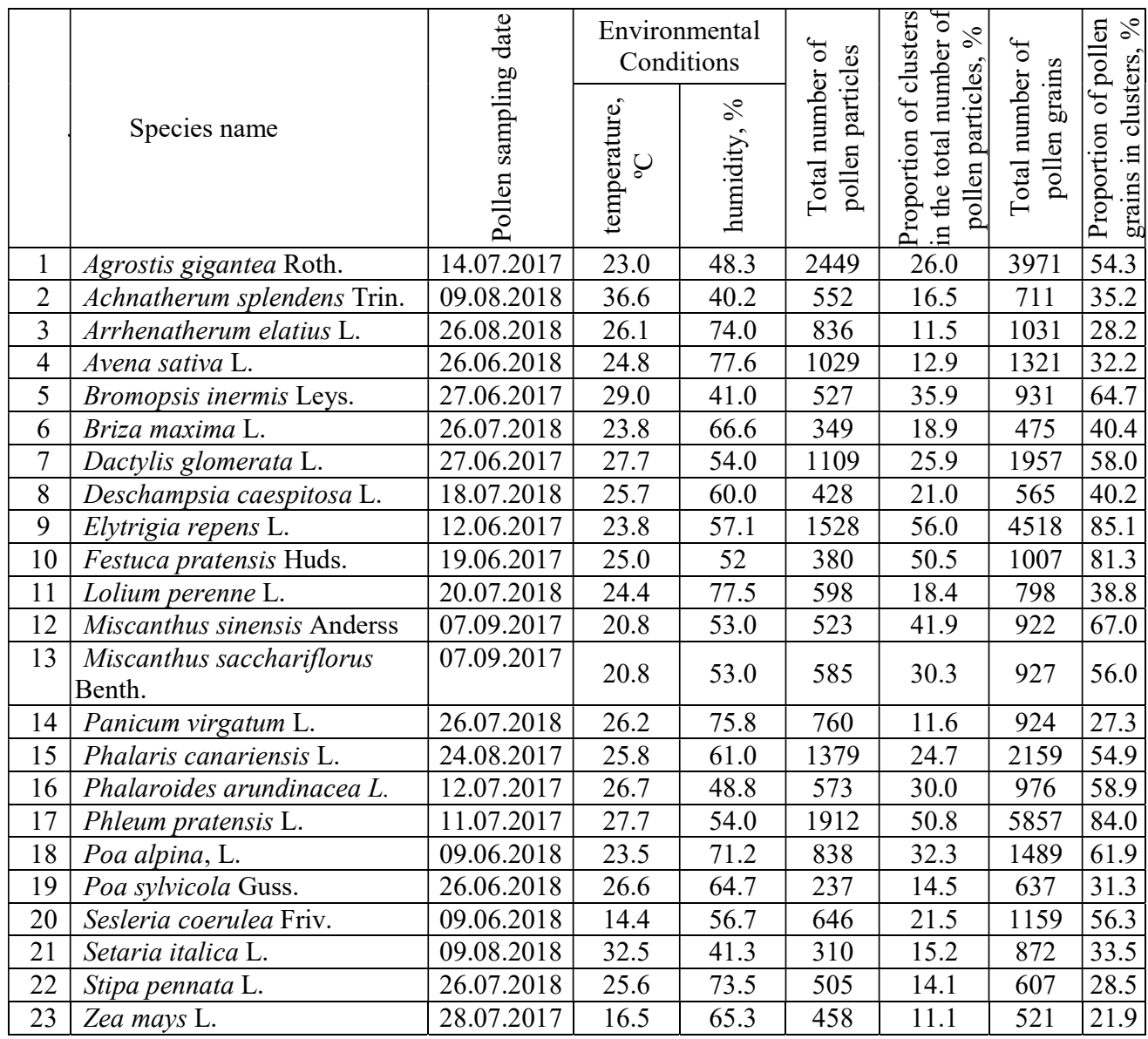

\section{Discussion}

The existing morphological properties of grasses, namely pollen grains with dry and smooth exine, without pronounced sculpturing, does not prevent the formation of clusters from two or more pollen grains. The statistical processing of the data unequivocally shows that the particles of this kind are formed not on the capturing substrate from single pollen grains in the process of their sedimentation, but directly in anthers in the process of grass pollen release into the atmosphere. The mechanism of such particles formation is not clear. One may suppose the mechanical adhesion of pollen grains in the process of deformation while drying, electrostatic interaction or other reasons. There is a significant variation both in the proportion of clusters in the total number of particles formed (11.1-50.8\%), and in the proportion of clustered pollen grains in the total quantity of pollen sedimented on substrates 
(21.9-84.0\%). It is possible to assume that the process of cluster formation depends on the size of pollen grains, relative air humidity and other factors. However, such clusters were observed in all esxperimental series, and the minimal proportion of clustered pollen grains exceeded $1 / 5$ of the total number of grains sedimented on the substrates.

The results obtained point that airborne grass pollen is not monodisperse but exists both as single pollen grains and their clusters, which can contain more than a half of the pollen grains produced (as it is the case with Elytrigia repens). The pollen component of air aerosol presents a whole spectrum of particles of each species, differing in the number of constituent grains and sedimentation rate. This factor is to be taken into consideration while estimating the distance of the drift of anemophilous plants' pollen and the risk of triggering allergy.

\section{References}

1. A.S. Safatov, G.A. Buryak, I.S. Andreeva, S.E. Olkin, I.K. Reznikova, A.N. Sergeev, B.D. Belan, M.V. Panchenko, Aerosol Sci. Technol, 407 (2010)

2. G. Erdtman, Handbook of Palynolody, 486 (1969)

3. V.V. Golovko, K.P. Kutsenogiy, M.A. Bizin, S.A. Popova, Atmos. Oceanic Opt, 26, 196 (2013)

4. D.A. Maria, V. Carolina, M. Antonio, M. Mauro, V. Alessandro, S. Alessandro, D.A. Gennaro, M. D'amato, S. Vitale, A. Molino, M. Mormile, A. Vatrella, A. Sanduzzi, G. D'amato, Int J Immunorehabilitation, 20, 5 (2018)

5. N.G. Astafieva, E.N. Udovichenko, I.V. Gamova, I.A. Perfilova, D.Y. Kobzev, RJA, 17 (2010)

6. I.R. Lake, N.R. Jones, M. Agnew, C.M. Goodess, F. Giorgi, F. Solomon, L. HamaouiLaguel, R. Vautard, M.A. Semenov, J. Storkey, M.M. Epstein, EHP, 125, 385 (2017)

7. S.M. Han, O.J. Won, K.S. Hwang, S.J. Suh, K.W. Park, B. Lee, C. Kim, TJPRC, 38, 397 (2015)

8. S.T. Jackson and M.E. Lypord, The botanical review, 65, 39 (1999)

9. D. Pohl, Beih Botanical Centra (in German), 56, 365 (1937)

10. Principles and methods of aeropalinological research (Moscow, 1999)

11. Allergy Service e in Europe (Stockholm, 1994)

12. V.V. Golovko, V.L. Istomin, K.P. Kutsenogiy, Atmos. Oceanic Opt, 28, 655 (2015)

13. V.V. Golovko, K.P. Kutsenogiy, V.L. Istomin, Atmos. Oceanic Opt, 26, 150 (2013) 